Pediat. Res. 2: 493-500 (1968)

Amino acids

fetus
Macaca mulatta

pregnancy

umbilical cord blood

\title{
The Free Amino Acids of Serum During Development of Macaca mulatta II. During Pregnancy and Fetal Life
}

\author{
GEORGE R. KERR ${ }^{[33]}$ \\ Department of Pediatrics and the Wisconsin Regional Primate Research Center, \\ University of Wisconsin, Madison, Wisconsin, USA
}

\begin{abstract}
Extract
The levels of free amino acids of serum have been investigated during pregnancy and fetal life in the rhesus monkey (Macaca mulatta). Samples of venous blood were drawn simultaneously from the mother and the umbilical cord of the fetus at cesarian section delivery performed at exactly 50, 75, 100, 125 , and 150 days conceptual age and at full-term vaginal delivery (168+4 days). Although a wide range of values was found for each amino acid at each age studied (tables I and II), certain trends were evident. All levels of maternal amino acids except those for taurine, lysine, 3- $\mathrm{CH}_{3}$-histidine and arginine were lower at full-term pregnancy than they were in nonpregnant adult animals. This pattern was apparent by 75 days of gestation and was maintained without further change during the remainder of pregnancy.

The sum of the individual values of all free amino acids in fetal blood was highest at 75 days of gestation; this resulted primarily from elevated levels of glutamine and glutamic acid, histidine, methionine, and valine. Levels of 3- $\mathrm{CH}_{3}$-histidine and glycine showed the opposite trend and were higher during late pregnancy than at 75 days of fetal age. The levels of the other amino acids did not undergo significant changes throughout gestation.

At each age studied, the level of each amino acid in fetal blood was higher than that of the corresponding level in maternal blood. The umbilical cord:maternal ratios for alanine, glutamine plus glutamic acid, leucine, 3- $\mathrm{CH}_{3}$-histidine and valine were significantly elevated at the earliest gestational age. The mean cord: maternal value for all amino acids studied showed a progressive decrease with increasing fetal maturity.
\end{abstract}

\section{Speculation}

The dynamics of fetal growth and development in most laboratory animals are sufficiently different from those in the human to make questionable their relevance to human fetal biology. It is generally acknowledged, however, that certain subhuman primates are similar to the human in many aspects of development. This study defines the changes in the free amino acids of serum of fetal and maternal blood that occur during normal pregnancy in the rhesus monkey, and indicates that this species may be used as a suitable experimental model to investigate protein and amino acid metabolism in experiments that cannot be performed during pregnancy and fetal life in the human. 


\section{Introduction}

Cellular growth and functional development reflect the incorporation of free amino acids during synthesis of structural and enzymic proteins. The maximal rate of growth occurs during fetal life, and a correspondingly rapid rate of nitrogen retention has been documented during this period [18]. The free amino acids of human fetal blood have been reported to reach highest levels during early pregnancy $[11,16]$; it is difficult to confirm these reports, however, or to investigate other aspects of normal fetal amino acid metabolism because of the limited availability of normal human fetuses. Fortunately, the placentae of several subhuman primates are structurally comparable to the human placenta, and these animals may be used to investigate the processes of fetal growth with some assurance that the data obtained will be pertinent to events characteristic of growth by the human fetus. As part of a collaborative study on fetal development in a laboratory primate, this communication will report the changes in the levels of free amino acids of serum that normally occur during pregnancy and fetal life in the rhesus monkey.

\section{Materials and Methods}

Female rhesus monkeys (Macaca mulatta) were maintained in individual cages under standard conditions of light, temperature, and humidity. All animals were fed a commercial chow [28], with daily supplements of milk [29], seasonal fruit, and vitamins [30]. Menstrual data and changes in weight and clinical health were recorded, and the date of conception established for all pregnancies [19]. Eight pregnant females were kept under constant supervision as the expected date of delivery approached ( $168 \pm 4$ days). Immediately following spontaneous vaginal delivery, simultaneous blood samples were drawn from the umbilical vein of the infant and a peripheral vein of the mother. In two instances, umbilical venous blood could not be obtained and blood was drawn from a femoral vein of the infant within 5 minutes after birth.

Twenty-five normal pregnancies were interrupted at exactly $50,75,100,125$, and 150 days of gestation by cesarean section deliveries performed under local anesthesia. Oral feedings were discontinued eight hours before the procedure, and maternal hydration was maintained during surgery by a slow intravenous infusion of $5 \%$ dextrose in $0.2 \%$ sodium chloride. Amniotic fluid was removed from the uterine cavity and the fetus was then delivered. Samples of venous blood were simultaneously drawn from the mother and from the umbilical cord of the infant.
Blood samples were kept at $5^{\circ}$ for 2 hours and centrifuged for 20 minutes at $5^{\circ}$. The serum was separated and stored at $-20^{\circ}$ until analyses were performed. Most samples were analyzed within 5 days. After acidification and high speed centrifugation of the serum by the method of GERRITSEN et al. [10], the free amino acids were determined by the method of SPACKMAN et al. [22] using a Beckman/Spinco automatic amino acid analyzer. An internal standard of beta-2-thienylalanine was incorporated with each analysis, and recovery of the standard in this series of experiments was $98.3 \pm$ $4.9 \%$ (mean \pm 1 standard deviation). Values for cystine and tryptophan are not reported because of instability during storage [8] and potential errors due to albumin-binding of tryptophan [10]. A decrease in plasma levels of glutamine and an increase in glutamic acid have been reported to occur coincident with storage [8]; although glutamine is also metabolized to compounds other than glutamic acid, values for these two amino acids were combined. Poor resolution was occasionally seen for arginine and $3-\mathrm{CH}_{3}$-histidine; the values for these amino acids should be accepted with reservation. The chromatographic peak of aspartic acid was occasionally superimposed upon the peak for threonine, preventing quantitation of both amino acids. The values for all amino acids analyzed, excluding those for aspartic acid and threonine, were combined at each gestational age and used as an indication of changes in the total free amino acid content of circulating body fluids. When values at two ages were compared, and subsequent to obtaining a significant $\mathrm{F}$ in analysis of variance, statistical analyses were performed by Student's t-test, defining significance at a level of $\mathrm{p}=<0.01$ [24].

\section{Results}

The Free Amino Acids of Maternal Serum During Pregnancy Values of free amino acid in seven fasting nonpregnant female monkeys and eight females at full-term vaginal delivery are presented in figure 1 . It was not possible to separate the chromatographic peaks for aspartic acid and threonine in the nonpregnant group, and values for these amino acids are not presented. Values for taurine, lysine, and $3-\mathrm{CH}_{3}$-histidine were higher in the parturition samples, but with the exception of these three amino acids and arginine, for which the values were similar, all values at full-term pregnancy were below those in the nonpregnant animals. The decrease was significant for glutamine plus glutamic acid, proline, glycine, serine, methionine, tyrosine, and histidine. The sum of the mean values for the 17 combined amino acids at full-term pregnancy was $35.82 \pm 8.75 \mathrm{mg} / 100 \mathrm{mI}$; in nonpregnant females, the 
Table I. Levels of free amino acids in maternal serum during pregnancy in Macaca mulatta $(\mathrm{mg} / 100 \mathrm{ml})^{1}$

\begin{tabular}{|c|c|c|c|c|c|c|c|}
\hline \multirow[b]{2}{*}{ Amino acids } & \multicolumn{6}{|c|}{ Gestational age } & \multirow[b]{2}{*}{$\begin{array}{c}\text { Nonpregnant } \\
\text { females (7) }\end{array}$} \\
\hline & 50 days $(5)^{2}$ & 75 days $(5)$ & 100 days $(5)$ & 125 days $(5)$ & 150 days $(5)$ & $\begin{array}{c}\text { Full-term } \\
\text { pregnancies } \\
168 \pm 4(8)\end{array}$ & \\
\hline Taurine & $5.49 \pm 1.20$ & $\cdot 4.75 \pm 1.44$ & $4.29 \pm 1.23$ & $3.99 \pm 1.03$ & $4.84 \pm 1.68$ & $4.25 \pm 1.68$ & $3.19 \pm 0.45$ \\
\hline Aspartic acid & $1.12 \pm 0.32$ & $0.72 \pm 0.17$ & $0.87 \pm 0.44$ & $0.67 \pm 0.01$ & $0.80 \pm 0.28$ & $1.04 \pm 0.47$ & - \\
\hline Threonine & $1.42 \pm 0.30$ & $0.91 \pm 0.08$ & $1.10 \pm 0.12$ & $1.37 \pm 0.26$ & $1.28 \pm 0.23$ & $1.25 \pm 0.32$ & - \\
\hline Serine & $2.07 \pm 0.50$ & $1.55 \pm 0.30$ & $1.77 \pm 0.50$ & $2.14 \pm 0.83$ & $1.78 \pm 0.42$ & $1.97 \pm 0.85$ & $3.50 \pm 0.87$ \\
\hline Glutamine and glutamic acid & $8.91 \pm 2.10$ & $6.18 \pm 0.73$ & $6.76 \pm 1.14$ & $6.83 \pm 1.13$ & $7.12 \pm 1.22$ & $7.17 \pm 1.41$ & $11.60 \pm 3.32$ \\
\hline Proline & $2.37 \pm 0.59$ & $2.96 \pm 0.70$ & $2.75 \pm 0.42$ & $2.59 \pm 0.59$ & $1.83 \pm 0.60$ & $2.10 \pm 0.90$ & $5.56 \pm 1.78$ \\
\hline Glycine & $3.17 \pm 0.62$ & $2.14 \pm 0.36$ & $2.41 \pm 0.27$ & $2.44 \pm 0.52$ & $2.44 \pm 0.49$ & $2.80 \pm 0.52$ & $5.27 \pm 1.51$ \\
\hline Alanine & $3.46 \pm 0.78$ & $2.39 \pm 0.28$ & $2.80 \pm 0.54$ & $3.01 \pm 0.96$ & $2.85 \pm 0.59$ & $2.81 \pm 0.56$ & $3.37 \pm 1.14$ \\
\hline Valine & $2.57 \pm 0.54$ & $1.61 \pm 0.25$ & $1.63 \pm 0.38$ & $1.73 \pm 0.30$ & $1.65 \pm 0.30$ & $2.01 \pm 0.87$ & $2.46 \pm 0.94$ \\
\hline Methionine & $0.73 \pm 0.11$ & $0.52 \pm 0.05$ & $0.48 \pm 0.14$ & $0.63 \pm 0.04$ & $0.48 \pm 0.07$ & $0.57 \pm 0.22$ & $0.90 \pm 0.25$ \\
\hline Isoleucine & $1.31 \pm 0.21$ & $0.79 \pm 0.16$ & $0.89 \pm 0.28$ & $0.96 \pm 0.22$ & $0.94 \pm 0.20$ & $0.99 \pm 0.36$ & $1.42 \pm 0.42$ \\
\hline Leucine & $2.21 \pm 0.44$ & $1.26 \pm 0.33$ & $1.44 \pm 0.47$ & $1.64 \pm 0.43$ & $1.75 \pm 0.47$ & $1.80 \pm 0.76$ & $2.59 \pm 0.61$ \\
\hline Tyrosine & $1.34 \pm 0.28$ & $0.97 \pm 0.25$ & $1.07 \pm 0.19$ & $1.27 \pm 0.18$ & $1.45 \pm 0.33$ & $0.93 \pm 0.28$ & $1.87 \pm 0.49$ \\
\hline Phenylalanine & $1.41 \pm 0.33$ & $0.83 \pm 0.20$ & $0.84 \pm 0.22$ & $0.99 \pm 0.19$ & $1.39 \pm 0.25$ & $1.26 \pm 0.49$ & $1.80 \pm 0.45$ \\
\hline Lysine & $2.58 \pm 0.81$ & $1.72 \pm 0.50$ & $1.74 \pm 0.55$ & $2.82 \pm 1.16$ & $1.94 \pm 0.81$ & $2.69 \pm 1.31$ & $1.56 \pm 0.59$ \\
\hline Histidine & $1.32 \pm 0.10$ & $1.23 \pm 0.20$ & $1.23 \pm 0.29$ & $1.49 \pm 0.33$ & $1.15 \pm 0.53$ & $1.03 \pm 0.27$ & $1.54 \pm 0.32$ \\
\hline 3- $\mathrm{CH}_{3}$-histidine & $0.62 \pm 0.10$ & $0.73 \pm 0.17$ & $0.84 \pm 0.15$ & $1.28 \pm 0.39$ & $1.20 \pm 0.47$ & $1.89 \pm 0.67$ & $0.83 \pm 0.44$ \\
\hline Arginine & $2.27 \pm 0.42$ & $1.39 \pm 0.71$ & $1.51 \pm 0.41$ & $1.58 \pm 0.41$ & $1.80 \pm 0.57$ & $1.90 \pm 1.05$ & $2.21 \pm 0.83$ \\
\hline Total value of 17 amino acids ${ }^{3}$ & $41.86 \pm 6.17$ & $31.02 \pm 3.31$ & $32.46 \pm 4.04$ & $35.08 \pm 4.68$ & $33.60 \pm 5.89$ & $35.82 \pm 8.75$ & $49.14 \pm 9.42$ \\
\hline
\end{tabular}

1 Figures indicate mean value $\pm 1 \mathrm{SD}$.

2 Figures in parentheses indicate number of animals studied at each age.

3 The values for aspartic acid and threonine are excluded from the total value. 


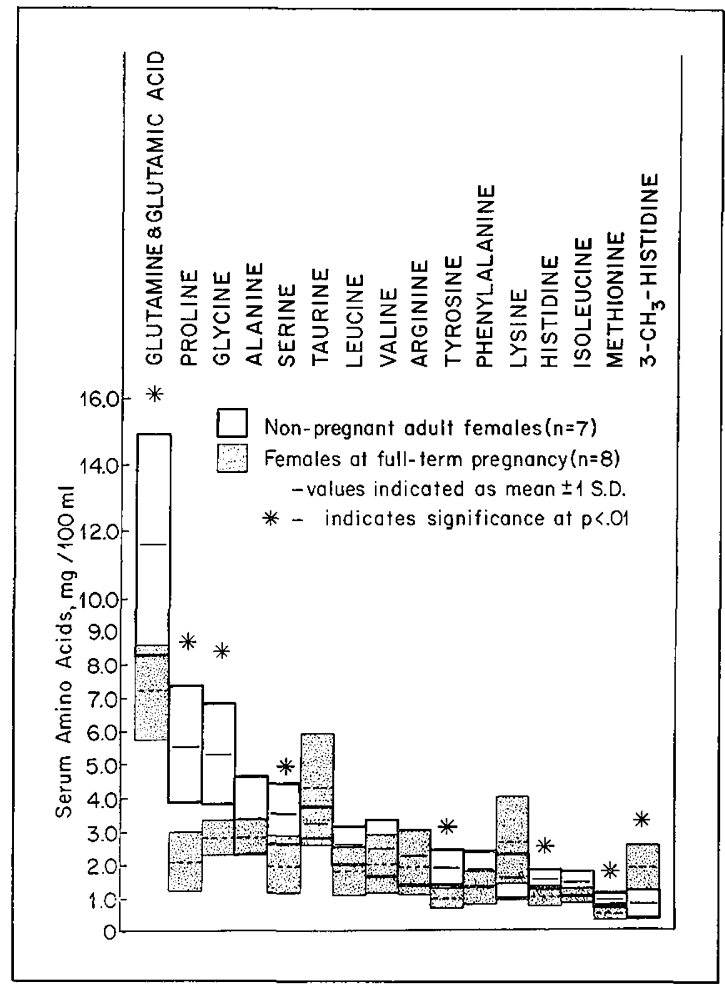

Fig. 1. The levels of free amino acids in serum in adult female rhesus monkeys. Stippled blocks indicate the mean values $\pm 1 \mathrm{SD}$ from monkeys at full-term pregnancy $(n=8)$. Open blocks indicate mean values $\pm 1 \mathrm{SD}$ from nonpregnant adult females $(\mathrm{n}=7)$. Asterisks indicate significant differences between the two values $(\mathrm{p}=<0.01)$.

value was $49.14 \pm 9.42 \mathrm{mg} / 100 \mathrm{ml}$. The ratio of pregnant: nonpregnant was 0.73 (table I).

A wide range of values was found at each gestational age. Analyses of maternal sera at earlier stages of pregnancy indicated that values for proline, glycine, serine, and tyrosine were reduced to levels below those characteristic of nonpregnant females by 50 days of gestation (table I). By 75 days, most of the amino acids showed a further reduction and, with the exception of taurine, lysine, and 3- $\mathrm{CH}_{3}$-histidine, the mean maternal values were equal to or greater than one standard deviation (SD) below the mean values in the nonpregnant animals (fig. 2).

The Free Amino Acids of Fetal Serum During Pregnancy

Values for the free amino acids of fetal serum at fullterm pregnancy in this species have been reported previously; values for taurine, lysine, and $3-\mathrm{CH}_{3}$-histidine

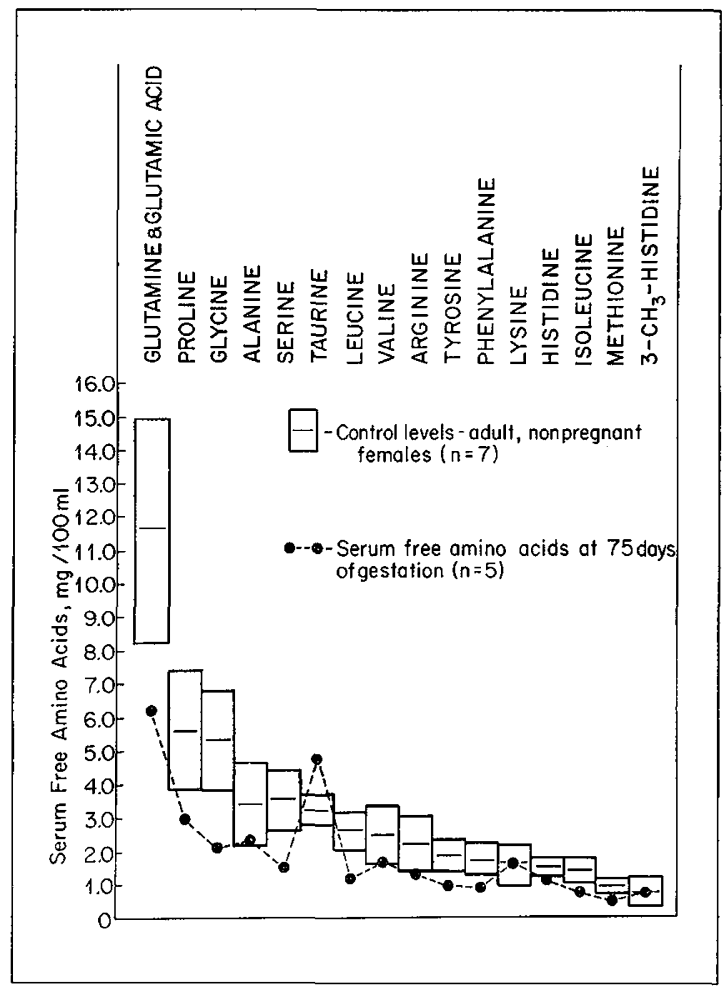

Fig. 2. The levels of free amino acids in serum in adult female rhesus monkeys. Blocks indicate mean values \pm 1 SD from seven nonpregnant monkeys. The broken line indicates mean maternal values at 75 days of gestation $(\mathrm{n}=5)$. were significantly higher, and those of leucine, serine and tyrosine were significantly lower in umbilical vein serum than they were in blood obtained at any other age during the first year of life [14]. Values for all other amino acids were within the control range. The total value of the 17 free amino acids of fetal sera at full-term gestation was $52.27 \pm 4.58 \mathrm{mg} / 100 \mathrm{ml}$ as compared with a level of $49.14 \pm 9.42 \mathrm{mg} / 100 \mathrm{ml}$ in the nonpregnant adult female.

It was not possible to obtain an adequate sample of blood from the fetuses at 50 days of age, but analyses of fetal sera at other stages of pregnancy indicated that levels of several amino acids, most notably glutamine plus glutamic acid, histidine, methionine, and valine, were significantly higher at 75 days of gestation than at full-term pregnancy; the total value of all amino acids studied was also highest in the 75-day-old fetuses (table II). Values for glycine and $3-\mathrm{CH}_{3}$-histidine 
The free amino acids of serum during development of Macaca mulatta. II. During pregnancy...

Table II. Levels of free amino acids of umbilical vein serum during pregnancy in Macaca mulatta $(\mathrm{mg} / 100 \mathrm{ml})^{1}$

\begin{tabular}{|c|c|c|c|c|c|c|}
\hline \multirow[b]{2}{*}{ Amino acids } & \multicolumn{6}{|c|}{ Gestational age } \\
\hline & 50 days & 75 days $(5)^{2}$ & 100 days $(5)$ & 125 days (5) & 150 days (5) & $\begin{array}{l}\text { Full-term } \\
\text { pregnancy } \\
(168 \pm 4) \\
(8)\end{array}$ \\
\hline Taurine & - & $6.36 \pm 0.64$ & $5.78 \pm 0.57$ & $5.75 \pm 1.01$ & $4.98 \pm 1.00$ & $5.38 \pm 1.24$ \\
\hline Aspartic acid & - & $0.92 \pm 0.15$ & $0.74 \pm 0.13$ & $0.67 \pm 0.04$ & $0.94 \pm 0.23$ & $1.28 \pm 0.60$ \\
\hline Threonine & - & $1.98 \pm 0.10$ & $1.81 \pm 0.37$ & $1.85 \pm 0.24$ & $1.99 \pm 0.39$ & $2.05 \pm 0.31$ \\
\hline Serine & - & $3.03 \pm 0.60$ & $2.18 \pm 0.61$ & $2.72 \pm 0.28$ & $3.04 \pm 0.66$ & $2.51 \pm 0.33$ \\
\hline \multicolumn{7}{|l|}{ Glutamine and } \\
\hline glutamic acid & - & $17.12 \pm 1.63$ & $14.40 \pm 2.13$ & $13.02 \pm 1.54$ & $12.31 \pm 1.96$ & $12.32 \pm 1.97$ \\
\hline Proline & - & $5.91 \pm 1.58$ & $4.88 \pm 1.13$ & $4.61 \pm 0.65$ & $3.50 \pm 1.20$ & $3.98 \pm 1.51$ \\
\hline Glycine & - & $2.76 \pm 0.25$ & $2.63 \pm 0.42$ & $2.87 \pm 0.39$ & $3.57 \pm 0.49$ & $4.40 \pm 0.60$ \\
\hline Alanine & - & $5.06 \pm 0.47$ & $4.59 \pm 0.64$ & $4.85 \pm 1.20$ & $4.12 \pm 0.71$ & $4.25 \pm 1.01$ \\
\hline Valine & - & $4.18 \pm 0.63$ & $3.26 \pm 0.39$ & $3.37 \pm 0.63$ & $3.52 \pm 0.33$ & $2.59 \pm 0.55$ \\
\hline Methionine & - & $0.96 \pm 0.12$ & $0.82 \pm 0.08$ & $0.98 \pm 0.34$ & $0.68 \pm 0.15$ & $0.72 \pm 0.12$ \\
\hline Isoleucine & - & $1.45 \pm 0.17$ & $1.25 \pm 0.17$ & $1.49 \pm 0.48$ & $1.44 \pm 0.30$ & $1.28 \pm 0.19$ \\
\hline Leucine & - & $2.45 \pm 0.51$ & $1.97 \pm 0.41$ & $2.18 \pm 0.83$ & $2.28 \pm 0.49$ & $2.02 \pm 0.46$ \\
\hline Tyrosine & - & $1.84 \pm 0.28$ & $1.83 \pm 0.23$ & $2.37 \pm 0.44$ & $2.33 \pm 0.41$ & $1.46 \pm 0.32$ \\
\hline Phenylalanine & - & $1.67 \pm 0.16$ & $1.45 \pm 0.26$ & $1.66 \pm 0.36$ & $1.77 \pm 0.24$ & $1.69 \pm 0.26$ \\
\hline Lysine & - & $4.59 \pm 0.58$ & $3.87 \pm 1.07$ & $5.23 \pm 0.94$ & $4.44 \pm 1.96$ & $4.47 \pm 1.50$ \\
\hline Histidine & - & $2.31 \pm 0.25$ & $2.07 \pm 0.45$ & $1.84 \pm 0.51$ & $2.02 \pm 0.62$ & $1.65 \pm 0.37$ \\
\hline 3- $\mathrm{CH}_{3}$-histidine & - & $1.48 \pm 0.56$ & $1.91 \pm 0.52$ & $2.38 \pm 0.38$ & $2.81 \pm 0.56$ & $2.32 \pm 0.61$ \\
\hline Arginine & - & $2.48 \pm 0.37$ & $2.28 \pm 0.61$ & $2.28 \pm 0.46$ & $1.97 \pm 0.61$ & $1.57 \pm 0.59$ \\
\hline \multicolumn{7}{|l|}{ Total value of } \\
\hline 17 amino acids $^{3}$ & - & $63.66 \pm 4.23$ & $55.16 \pm 3.34$ & $57.61 \pm 3.62$ & $53.81 \pm 8.53$ & $52.57 \pm 4.58$ \\
\hline
\end{tabular}

${ }^{1}$ Figures indicate mean value $\pm 1 \mathrm{SD}$.

${ }^{2}$ Figures in parentheses indicate number of animals studied at each age.

${ }^{3}$ The values for aspartic acid and threonine are excluded from the total value.

showed the opposite trend, with significantly higher values at full-term delivery than at 75 days of gestation. The other amino acids did not demonstrate significant changes during this period of study.

The Umbilical Cord:

Maternal (G:M) Ratios

for Free Amino Acids

During Pregnancy

The G: $M$ ratios for each free amino acid are presented in table III. It is apparent that at each stage of pregnancy, each amino acid is found at higher levels in umbilical venous blood than in maternal blood. The ratios for alanine, glutamine plus glutamic acid, leucine, 3- $\mathrm{CH}_{3}$-histidine and valine were significantly higher at 75 days of gestation than during late pregnancy; the mean $\mathrm{G}: \mathrm{M}$ ratio showed a progressive decrease with increasing fetal maturity (table III).

\section{Discussion}

The free amino acids of serum are primarily important as they reflect and contribute to the intracellular amino acid pool. Nitrogen retention [18] and the rates of cell division [25] are maximal during fetal life. ZAMEGNIK et al. [27] noted that both malignant and fetal liver cells incorporated amino acids at a more rapid rate than did the cells of adult liver. VAN SLyKe and MEXER [23] reported that increasing the extracellular levels of free amino acids by artificial means produced an even greater increase in the intracellular levels of these compounds. Christensen and STREICHer [4] confirmed this observation, suggesting that protein synthesis might be promoted by elevated circulating levels of free amino acids, and Schrerer [20] has concluded that 'the level of amino acid in the fetal blood is a function of the growth rate of the fetus in utero'. As 
Table III. Ratio of levels of free amino acids, umbilical cord blood: Maternal blood, during pregnancyin Macaca mulatta ${ }^{1}$

\begin{tabular}{|c|c|c|c|c|c|c|}
\hline \multirow[b]{2}{*}{ Amino acids } & \multicolumn{6}{|c|}{ Gestational age } \\
\hline & 50 days & 75 days $(5)^{2}$ & 100 days (5) & 125 days $(5)$ & 150 days $(5)$ & $\begin{array}{l}\text { Full-term } \\
\text { pregnancy } \\
(168 \pm 4 \text { days }) \\
(8)\end{array}$ \\
\hline Taurine & 一 & $1.43 \pm 0.36$ & $1.45 \pm 0.44$ & $1.52 \pm 0.35$ & $1.09 \pm 0.24$ & $1.34 \pm 0.27$ \\
\hline Aspartic acid & - & $1.30 \pm 0.12$ & $1.01 \pm 0.35$ & $1.03 \pm 0.06$ & $1.69 \pm 1.07$ & $1.32 \pm 0.42$ \\
\hline Threonine & - & $2.20 \pm 0.14$ & $1.71 \pm 0.58$ & $1.40 \pm 0.31$ & $1.47 \pm 0.07$ & $1.71 \pm 0.34$ \\
\hline Serine & - & $2.00 \pm 0.52$ & $1.28 \pm 0.39$ & $1.39 \pm 0.36$ & $1.75 \pm 0.48$ & $1.43 \pm 0.43$ \\
\hline Glutamine and & & & & & & \\
\hline glutamic acid & - & $2.73 \pm 0.16$ & $2.19 \pm 0.50$ & $1.93 \pm 0.31$ & $1.74 \pm 0.23$ & $1.81 \pm 0.56$ \\
\hline Proline & - & $1.98 \pm 0.22$ & $1.76 \pm 0.20$ & $1.80 \pm 0.19$ & $1.96 \pm 0.47$ & $1.92 \pm 0.47$ \\
\hline Glycine & - & $1.30 \pm 0.14$ & $1.09 \pm 0.12$ & $1.20 \pm 0.19$ & $1.72 \pm 0.66$ & $1.59 \pm 0.23$ \\
\hline Alanine & - & $2.13 \pm 0.10$ & $1.68 \pm 0.37$ & $1.63 \pm 0.19$ & $1.47 \pm 0.20$ & $1.54 \pm 0.32$ \\
\hline Valine & - & $2.60 \pm 0.20$ & $2.05 \pm 0.27$ & $1.94 \pm 0.11$ & $2.03 \pm 0.50$ & $1.66 \pm 0.54$ \\
\hline Methionine & - & $1.85 \pm 0.16$ & $1.92 \pm 0.79$ & $1.55 \pm 0.51$ & $1.39 \pm 0.21$ & $1.42 \pm 0.46$ \\
\hline Isoleucine & - & $1.85 \pm 0.11$ & $1.49 \pm 0.35$ & $1.53 \pm 0.30$ & $1.54 \pm 0.20$ & $1.40 \pm 0.39$ \\
\hline Leucine & - & $1.95 \pm 0.12$ & $1.42 \pm 0.34$ & $1.30 \pm 0.25$ & $1.32 \pm 0.16$ & $1.22 \pm 0.32$ \\
\hline Tyrosine & - & $1.96 \pm 0.31$ & $1.79 \pm 0.45$ & $1.88 \pm 0.39$ & $1.62 \pm 0.22$ & $1.67 \pm 0.52$ \\
\hline Phenylalanine & - & $2.05 \pm 0.25$ & $1.79 \pm 0.40$ & $1.67 \pm 0.16$ & $1.30 \pm 0.28$ & $1.50 \pm 0.55$ \\
\hline Lysine & - & $2.79 \pm 0.53$ & $2.26 \pm 0.31$ & $2.06 \pm 0.63$ & $2.26 \pm 0.51$ & $1.85 \pm 0.59$ \\
\hline Histidine & - & $1.92 \pm 0.27$ & $1.73 \pm 0.41$ & $1.33 \pm 0.54$ & $1.82 \pm 0.27$ & $1.75 \pm 0.40$ \\
\hline 3- $\mathrm{CH}_{3}$-histidine & - & $2.00 \pm 0.34$ & $2.28 \pm 0.58$ & $2.01 \pm 0.56$ & $2.34 \pm 0.81$ & $1.35 \pm 0.20$ \\
\hline Arginine & - & $2.05 \pm 0.65$ & $1.69 \pm 0.84$ & $1.63 \pm 0.43$ & $1.06 \pm 0.17$ & $1.56 \pm 0.99$ \\
\hline Mean $\mathrm{G}: \mathrm{M}$ value $^{3}$ & - & $2.04 \pm 0.39$ & $1.74 \pm 0.33$ & $1.65 \pm 0.26$ & $1.65 \pm 0.37$ & $1.56 \pm 0.20$ \\
\hline
\end{tabular}

${ }^{1}$ Figures indicate mean value $\pm 1 \mathrm{SD}$.

${ }^{2}$ Figures in parentheses indicate the number of studies at each age.

3 The values for aspartic acid and threonine are excluded from the mean value.

amino acids are maintained at higher levels in the fetus than in the maternal organism, any change in the circulating free amino acids in either fetal or maternal body fluids, or in the mechanisms for their transplacental transport, may have significant effects on the rates of fetal protein synthesis, cell division, and growth.

Reduced levels of total $\alpha$-amino nitrogen in maternal blood were reported during human pregnancy by several investigators $[1,2,6]$. Christensen et al. [5] showed that this reflected reduced values for most of the individual amino acids. This finding has been confirmed subsequently in a variety of related studies [9, $11,17,21]$. The timing of the decrease has not been established, but Bosnes [1] reported that levels of the amino acid in maternal blood were reduced from the ninth week of human gestation until delivery. Both he and BURT [2] reported a rapid rise following parturi- tion. Data from pregnant monkeys indicated that the characteristic pattern of hypoaminoacidemia had been established by the 75th day of gestation. The observation that values for taurine, lysine, 3- $\mathrm{CH}_{3}$-histidine and arginine are not decreased during pregnancy in this species cannot be explained at present.

The free amino acids in umbilical cord blood are a reflection of placental transport processes, placental structural integrity, maternal diet, levels of free amino acid in maternal blood, and fetal metabolic processes. Lichtenstern [16] demonstrated that the level of amino nitrogen in cord blood was highest in the most immature fetuses. This observation was supported by Ghadimi and Pecora [11], who reported levels for the individual amino acids. A similar trend for levels of amino acids to be higher in the most immature fetuses was also seen in the rhesus monkey and was most notable for glutamine plus glutamic acid, histidine, me- 
thionine and valine. Glycine and 3- $\mathrm{CH}_{3}$-histidine showed the opposite trend, but most of the other amino acids showed little change. The reasons for these changes in the circulating free amino acids during the various stages of fetal life have not been established, but presumably indicate changing patterns of amino acid metabolism.

Numerous studies have demonstrated that each amino acid is maintained at higher levels in fetal blood than in maternal blood $[3,4,7,9,11,12,17,20,26]$. This has occurred even in the face of an elevation in the level of amino acid in maternal blood $(4,13,15]$. Ghadrmi and Pegora [11], Christensen and Streicher [4], and Clemetson and Ghurchman [6] noted the mean $\mathrm{C}: \mathrm{M}$ ratio at full-term delivery in the human to be 1.6-1.7. LindBlad [17] reported a mean C:M ratio of 1.9. The mean ratio of 1.54 defined in this study is generally comparable. The ratios for taurine, lysine, and $3-\mathrm{CH}_{3}$-histidine at full-term pregnancy were produced primarily by increased levels in the fetus. The ratio for alanine was produced jointly by maternal hypoaminoacidemia and slight fetal hyperaminoacidemia. For all other amino acids, the ratios were produced by low values in maternal blood in association with normal values in cord blood.

The $\mathrm{C}: \mathrm{M}$ ratios for taurine, lysine and arginine are considerably higher at full-term pregnancy in the human than in the rhesus monkey $[3,11,12,17]$. An explanation for these differences is not apparent, but with these exceptions, the $\mathrm{C}: \mathrm{M}$ ratios demonstrated by the rhesus monkey at full-term pregnancy are similar to those reported for the human. GHadim and Pecora [11] reported that the $G: M$ ratios for several amino acids were greatest during early pregnancies. The ratios for alanine, glutamine plus glutamic acid, leucine, 3- $\mathrm{CH}_{3}$-histidine and valine were increased significantly during early gestation in the rhesus monkey and the mean $C: M$ values showed a progressive decrease with advancing gestation.

In order to gain knowledge of the processes of fetal growth and development, it is first necessary to study normal fetuses. Such a project has obvious limitations in the human, and data derived from infants born by abortion or miscarriage must raise doubt as to the normality of the tissues. Fortunately, with appropriate recognition of taxonomic differences, several subhuman primates appear to offer satisfactory models for the study of many of the parameters of fetal growth and development that need to be defined in man. In this species, the levels of several amino acids are notably higher in serum of maternal and fetal blood than are those of the human $[11,17]$. This difference may be partly explained on a methodological basis, since Gerritsen et al. [10] reported that their modification of the deproteinization procedure of SPAGKMAN, STEIN and MOORE [22] resulted in higher recoveries for most amino acids in comparison with results obtained after deproteinization with either $1 \%$ picric acid or $4.5 \%$ sulphosalicylic acid. The possibility that the increased values found in monkey serum may represent 'leakage' of amino acids from hematologic elements must also be considered [21]. Whether these discrepancies reflect species differences, or procedural and methodological differences, cannot be defined at the present time. It is apparent, however, that enough similarities exist between the two species to recommend the pregnant rhesus monkey for studies of amino acid metabolism that cannot be performed in human pregnancies.

Summary

The free amino acids of serum have been studied during pregnancy and fetal life in the rhesus monkey. Levels of all amino acids in maternal blood, except those of taurine, lysine, 3- $\mathrm{CH}_{3}$-histidine, and arginine, were lower at full-term pregnancy than in nonpregnant adult females. This characteristic pattern of amino acids was evident by the 75 th day of gestation. Levels of taurine, lysine, and 3- $\mathrm{CH}_{3}$-histidine were higher, and those of leucine, serine, and tyrosine were lower in umbilical vein blood than they were during the remainder of the first year of life [14]; other amino acids in cord blood were within the normal range. Levels of glutamine plus glutamic acid, histidine, methionine, and valine were significantly elevated in the blood of more immature fetuses. The ratio of amino acid levels in umbilical and maternal serum ( $\mathrm{G}: \mathrm{M}$ ratio) was greater than unity for each amino acid. The $\mathrm{C}$ : $\mathrm{M}$ ratio for alanine was due to reduced levels in maternal blood and a slightly elevated level in cord blood; the ratio for taurine, lysine, and 3- $\mathrm{CH}_{3}$-histidine was primarily due to elevated levels in fetal blood. The C: $M$ ratios for all other amino acids at full-term pregnancy were due to reduced levels in maternal blood. The $\mathrm{G}$ : $\mathrm{M}$ ratios for alanine, glutamine plus glutamic acid, leucine, 3- $\mathrm{CH}_{3}$-histidine, and valine were significantly higher during early pregnancy, and the average $\mathrm{C}: \mathrm{M}$ ratio for the mean values of each amino acid showed a progressive decrease with advancing gestation.

\section{References and Notes}

1. Bosnes, R.W.: The plasma amino acid and amino nitrogen concentration during normal pregnancy, labor, and early puerperium. J. biol. Chem. 168: 345 (1947).

2. Burt, R.L.: 'Combined' and free plasma alphaamino nitrogen in normal pregnancy and toxemia. Amer.J. Obstet. Gynec. 65: 304 (1953). 
3. Butterfield, L.J. and O'Brien, D.: The effect of maternal toxaemia and diabetes on transplacental gradients of free amino acids. Arch. Dis. Childh.:38: 326 (1963).

4. Girristensen, H.N. and Streicher, J.A.: Association between rapid growth and elevated cell concentrations of amino acids. I. In fetal tissues. J. biol. Chem. 175: 95 (1948).

5. Christensen, P.J.; Date, J.W.; Schønheyder, F. and Volqvartz, K. : Amino acids in blood plasma and urine during pregnancy. Scand.J.clin. Lab. Invest. 9: 54 (1957).

6. Glemetson, C.A.B. and Churchman, J.: The placental transfer of amino-acids in normal and toxemic pregnancy. J. Obstet. Gynaec. brit. Cwlth. 61: (1954).

7. Crumpler, H. R.; Dent, C. E. and Lindan, O.: The amino-acid pattern in human foetal and maternal plasma at delivery. Biochem. J. 47: 223 (1950).

8. Dickinson, J.C.; Rosenblum, H. and Hamilton, P.B.: Ion exchange chromatography of the free amino acids in the plasma of the newborn infant. Pediatrics 36: 2 (1965).

9. Furuya, H. and Maehara, D.: Amino acid concentration in maternal and fetal serum. J.jap.obstet. gynaec. Soc. 11: 167 (1964).

10. Gerritsen, T.; Rehberg, M.L. and Waisman, H.A.: On the determination of free amino acids in serum. Analyt. Biochem. 11: 460 (1965).

11. Ghadimi, H. and Pecora, P.: Free amino acids of cord plasma as compared with maternal plasma during pregnancy. Pediatrics 33: 500 (1964).

12. Glendening, M.B.; Margolis, A.J. and Page, E.W.: Amino acid concentrations in fetal and maternal plasma. Amer.J.Obstet. Gynec. 81: 591 (1961).

13. KANG, E. and PAINe, R.S.: Elevation of plasma phenylalanine levels during pregnancies of women heterozygous for phenylketonuria. J.Pediat. 63: 283 (1963).

14. KERR, G.R.: The free amino acids of serum during development of $M$. mulatta. I. During the first year of life. Pediat. Res. 2: 187 (1968).

15. Kerr, G. R.; Ghamove, A. S.; Harlow, H.F. and WaIsman, H.A.: 'Fetal PKU': The effect of maternal hyperphenylalaninemia during pregnancy in the rhesus monkey (Macaca mulatta). Pediatrics 1968 (in press 1968).

16. Lichtenstein, A.: Untersuchungen an Nabelschnurblut bei frühgeborenen und ausgetragenen Kindern mit besonderer Berücksichtigung der Aminosäuren. Z. Kinderheilk. 51: 748 (1931).

17. Lindblad, B.S. and Baldesten, A.: The normal venous plasma free amino acid levels of non-pregnant women and of mother and child during delivery. Acta paediat., Uppsala 56: 37 (1967).

18. Moulton, G.R.: Age and chemical development in mammals. J. biol. Chem. 57: 79 (1923).

19. Ponce de Lugo, G. G.: Length of menstrual cycles in relation to time of successful mating in Macaca mulatta. Biol. Neonat. 6: 104 (1964).

20. Schreier, K.: Some peculiarities of amino acid metabolism in infancy and early childhood. J. Pediat. 46: 86 (1955).

21. Soupart, P.: Free amino acids of blood and urine in the human; in Amino acid pools (ed. Holden, J.T.), p. 220 (Elsevier, New York 1962).

22. Spackman, D.H.; Stein, W.H. and Moore, S.: Automatic recording apparatus for use in the chromatography of amino acids. Analyt. Chem. 30: 1190 (1958).

23. VAN Slyke, D.D. and Meyer, G. M.: The fate of protein digestion products in the body. III. The absorption of amino-acids from the blood by the tissues. J. biol. Chem. 16: 197 (1913).

24. WINER, B.J.: Statistical principles in experimental design (McGraw-Hill, New York 1962).

25. Winick, M. and Noble, A.: Cellular response in rats during malnutrition at various ages. J. Nutr. 89: 300 (1966).

26. WrRTSGHAFTER, Z.T.: Free amino acids in human amniotic fluid, fetal and maternal serum. Amer.J. Obstet. Gynec. 76: 1219 (1958).

27. Zamecnik, P. C.; Frantz, I.D., Jr.; LofTsfield, R.B. and Stephenson, M.L.: Incorporation in vitro of radioactive carbon from carboxyl-labeled DL-alanine and glycine into proteins of normal and malignant rat livers. J.biol. Chem. 175: 299 (1948).

28. Purina Monkey Chow ${ }^{\circledR}$, Ralston Purina Company, St. Louis, Missouri.

29. Similac ${ }^{\circledR}$, Ross Laboratories, Columbus, Ohio.

30. Paladac ${ }^{\circledR}$, Parke, Davis, and Co., Detroit, Michigan.

31. The surgical assistance of Drs. JAmes R. Allen, Alfred L. Kennan, and Harry A. Warsman, and the technical assistance of Mr. James A. CAMPBelL and Mr. Guenther Scheffler are gratefully acknowledged.

32. Supported by grant FR-00167 from the National Institutes of Health to the Wisconsin Regional Primate Research Center.

33. Requests for reprints should be addressed to: George R.KerR, M.D., Regional Primate Research Center, University of Wisconsin, $1223 \mathrm{Ca}$ pitol Court, Madison, Wis. 53706 (USA). 